\title{
Seasonal dynamics of common ground beetles (Coleoptera: Carabidae) along an urbanisation gradient near Sorø, Zealand, Denmark
}

\author{
Zoltán Elek, Andy G. Howe, Mattias K. Enggaard \& Gábor L. Lövei
}

Elek, Z., Howe, A. G., Enggaard, M. K. \& Lövei, G. L. 2017: Seasonal dynamics of common ground beetles (Coleoptera: Carabidae) along an urbanisation gradient near Sorø, Zealand, Denmark. — Entomol. Fennica 28: 27-40.

The seasonal activity of six carabid species (Nebria brevicollis, Carabus nemoralis, C. hortensis, C. coriaceus, Pterostichus melanarius and Abax parallelepipedus) was studied along an urbanisation gradient (rural forest - suburban forest - forest fragments in urban park) in Sorø, Denmark, during April-October 2004 and 2005. Two groups were identified: 1) Species with constant seasonality, in which seasonal activity profiles did not differ along the gradient (C. hortensis, C. coriaceus, and A. parallelepipedus); 2) Species with flexible seasonality, with remarkable differences along the gradient and between the years $(C$. nemoralis, $N$. brevicollis and P. melanarius). In four out of six studied species, 2005 was less favourable than 2004. Spring activity in the urban habitat started earlier than in the suburban or forested ones. A better understanding of urban green infrastructures in biodiversity assessments may need the study of seasonality in order to distinguish whether the bioindicator's responses are to habitat quality or stochastic seasonal events.

Z. Elek, Department of Agroecology, Aarhus University, Flakkebjerg Research Centre, DK-4200 Slagelse, Denmark; MTA-ELTE-MTM Ecology Research Group, Hungarian Academy of Sciences, clo Biological Institute, Eötvös Loránd University, Pázmány Péter sétány 1/C., H-1117 Budapest; and Hungarian Natural History Museum, Baross u. 13., H-1088 Budapest, Hungary; E-mail: zoltan.elek2@gmail.com

A. G. Howe. Roskilde University Centre, Department of Life Sciences and Chemistry, DK-4000, Roskilde, Denmark; Current address: Institute of Biology, Department of Geosciences and Natural Resource Management, University of Copenhagen, Universitetsparken 15, DK-2100 Copenhagen, Denmark

M. K. Enggaard, Roskilde University Centre, Department of Life Sciences and Chemistry, DK-4000, Roskilde, Denmark; Current address: 909 Duke Street, Alexandria, 22314 VA, USA

G. L. Lövei, Department of Agroecology, Aarhus University, Flakkebjerg Research Centre, DK-4200 Slagelse, Denmark

Received 9 June 2015, accepted 25 October 2016 


\section{Introduction}

Ground beetles are a species-rich family of Coleoptera, forming a significant part of the fauna active at ground surface within most of their area of distribution (Lövei \& Sunderland 1996). A total of 136 carabid species are known from Denmark (Lindroth 1985, 1986), but their population dynamics and life-histories are not well documented. The pioneering studies by SchjøtzChristensen (e.g. 1965, 1968) clarified basic aspects of selected species in a heath area on Jutland, including reproductive activity and life span. Gyldenkaerne and Ravn (1998), based on studies in NW Europe, presented a qualitative graphical summary of the seasonal activity of the most common species on agricultural land. More recent studies on ground beetles concentrate on the fauna of agricultural land (Lövei et al. 2002, 2005, Lövei \& Magura 2016), and urban habitats (Elek \& Lövei 2005, 2007). However, there remains a scarcity of published quantitative lifehistory studies on the native ground beetle fauna (but see Jørum 1976a, 1980). Quantitative descriptive methods are available (e.g. Fazekas et al. 1997), and climate change-related concerns make it relevant to have a more precise understanding of the spatial and temporal variation in the seasonal dynamics of species, including ground beetles. These beetles are good ecological indicators because of their well-established taxonomy and ecology; they also have a key function in terrestrial ecosystems such as abundant generalist predators of arthropods and seeds (Lövei \& Sunderland 1996, Kulkarni et al. 2015). Given that several species are protected, information on their seasonal dynamics would be useful to harmonise conservation efforts during habitat management operations, like the use of chemicals in agricultural lands, forest management, etc., in order to minimise risk to ground beetles.

A large number of ground beetles were collected within the framework of Danglobe Project (Elek \& Lövei 2005) aiming to study the effects of urbanisation on ground beetles. Similarly to other studies (Niemelä et al. 2002, Vergnes et al. 2014), this study revealed that the urbanisation has a negative effect on the large forest species as their species richness and abundance decrease towards the urban habitats (Elek \& Lövei 2007,
Croci et al. 2008). However, the activity of the generalist and open habitat species increases in the more urbanised habitats. These results prompted us to investigate the seasonal dynamics of the most abundant carabid species among the sites in order to distinguish the local/temporal variability from the consequent trend in the changes (abundance and species richness) of ground beetle assemblages. As a starting point, in this paper we aim to describe the seasonal dynamics, in a standardised way (Fazekas et al. 1997), of the most common carabid species from Sorø, West Zealand, Denmark. We also examined the hypothesis that due to the "heat island" effect of cities (Mcdonnell \& Hahs 2008), the six common species that were present at more than one urbanisation stage would start their spring activity earlier than in their original forest habitat. We found considerable variation in seasonal dynamics, both in space and time, but this did not support our hypothesis: in most situations examined, spring activity started earlier in the original forest habitat than in the suburban or urban one. Forest fragments in the urban area served as source habitats for one species, Nebria brevicollis (Fabricius).

\section{Materials and methods}

\subsection{Sampling area and methods}

Our study area was in and around the town of Sorø (92.1 inhabitants $/ \mathrm{km}^{2}$ ), about $80 \mathrm{~km}$ west of Copenhagen, on the island of Zealand (Fig. 1). The forest, suburban and urban sampling areas were all located in parts of a once continuous beech forest surrounding the city. The closest trapping block in the rural forest was about 1.5 $\mathrm{km}$ west from the town centre. The suburban forest 1 extended from north-east of the town centre toward south-east, and the closest trapping block was about $1.01 \mathrm{~km}$ from the town centre. The $s u b$ urban forest 2 was located south of the town centre with the closest trapping block about 2.17 $\mathrm{km}$ from the town centre. The dominant trees were beech (Fagus sylvatica L.) and hornbeam (Carpinus betulus L.). The urban area was in the park of the Sorø Akademi. This park has old forest patches (mainly with beech), individual rem- 
Fig. 1. Overview of the sampling sites in Sorø, Denmark, based on the aerial photograph from 2005. Black lines designate sampled forest areas, suburban forest 2 was sampled only in 2005. Black square designates town centre.

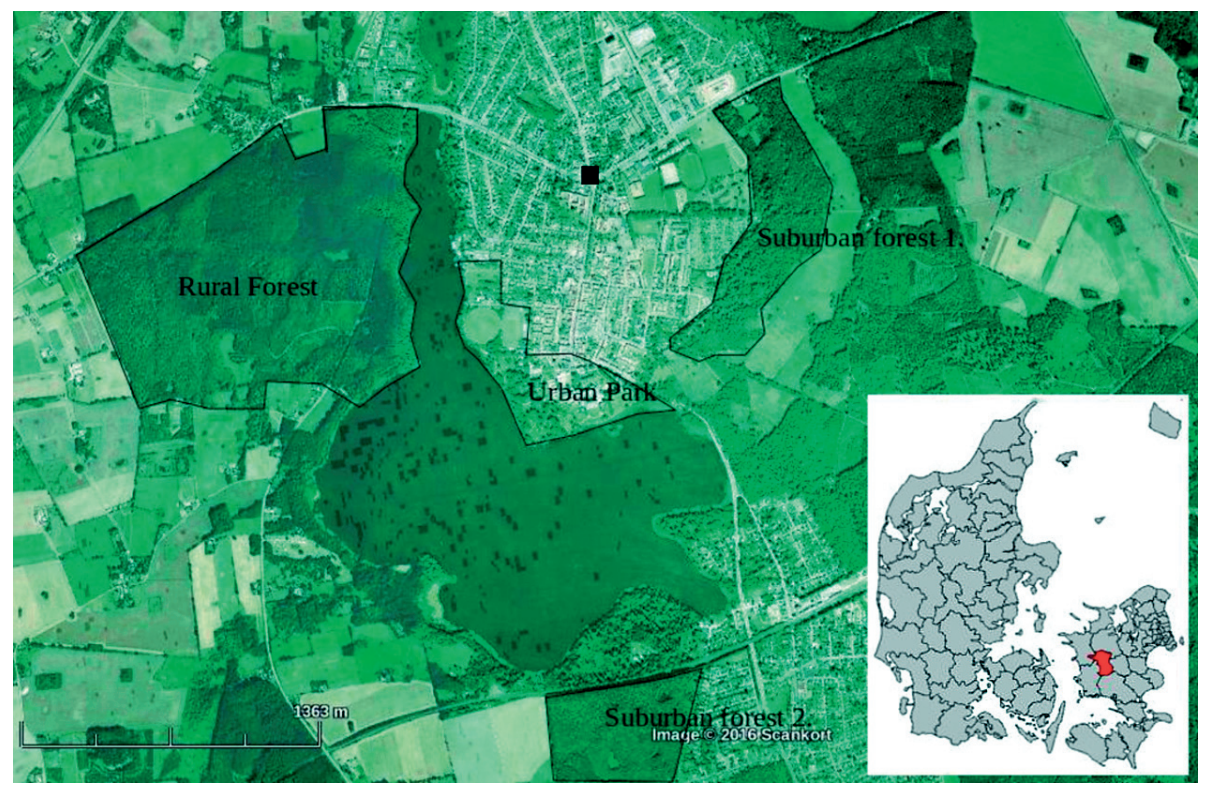

nant trees, tall exotic trees, alternating with bushes and extensive mown grass areas. All traps were set in forest patches that had at least some large trees that could be assumed to have remained there since the time the whole area was forested ca. 250 years ago. The traps were always set $>5 \mathrm{~m}$ from the nearest edge.

The material was collected following the Globenet protocol (Niemelä et al. 2000). This setup requires four groups of 10 traps per urbanisation stage, set at distances that ensure spatial independence. The traps were checked fortnightly between the end of April to mid-October, 2004, giving a trapping effort of 2,640 trap-weeks (120 traps $\times 22$ weeks). In order to examine the impact of reduced sampling effort we operated the traps every second fortnight in 2005 (see details of the results in Sapia et al. 2006), resulting to the total sampling effort of 1,440 trap-weeks (120 traps $\times$ 12 weeks). In 2005, the suburban forest 2 was sampled in addition to the suburban forest 1 because the size of the suburban forest 1 was reduced due to logging. The species composition was highly similar in these two suburban areas, based on non-metric multidimensional scaling (Elek \& Lövei 2007). For identification, keys by Lindroth $(1985,1986)$ and Hůrka (1996) were used. Further details about the sampling are presented by Elek and Lövei (2005).

\subsection{Seasonal activity}

Seasonal activity was described by the "quartile method" according to Fazekas et al. (1997). Captures (total number of individuals per fortnight) were first converted to cumulative values. To mitigate the impact of time-specific weather anomalies, the unweighted running means of three weeks were calculated the following way:

$\ddot{X}_{a}=\left(x_{a-1}+x_{a}+x_{a}+1\right) / 3$

where $x_{a-1}$ is the number of captures during the week before, and $x_{a+1}$ is the same for the week following the central one, whose capture is $\mathrm{x}_{\mathrm{a}}$.

This running mean was used to calculate cumulative capture data, and the major dates (hereafter cardinal dates) of the seasonal activity were established. The three cardinal dates of the activity curve are the start, peak and end of the main activity period. The date of peak activity is the date when the cumulative number of individuals caught reached $50 \%$ of the total numbers collected. The beginning and the end of the main activity period were defined as the dates when 25\% and $75 \%$, respectively, of the total number of individuals were captured. The "early activity peri$o d$ " extended from the start of the activity to the beginning of the main activity period, and the 
"late activity period" was defined as the period after the end of the main activity period until the activity had ceased. Only the activity of species with at least 10 individuals/site×year were considered, and the quartile method applied only to the species with a unimodal activity curve.

\section{Results}

\subsection{Total seasonal activity}

The total catch was 10,314 individuals belonging to 43 species in 2004, and 4,961 individuals of 38 species in 2005 (for details see Elek \& Lövei 2005). Generally, ground beetle activity was lower in 2005 than in 2004, except in the suburban habitats (Fig. 2). The total numbers captured were the highest in the urban habitat in both years (4,424 and 1,936 individuals in 2004 and 2005, respectively).

In the forest, ground beetle activity was strongly unimodal in both years, with high activity in mid- to late August (Fig. 2). The autumn activity was higher in the forest than in the urban habitat (Fig. 2). The activity density was the lowest in the suburban areas (2004: 1,591 ind.; 2005: 1,274 ind.), and showed a slight increase late in the season in both years, more in 2005 (Fig. 2). In the urban habitat, ground beetles showed bimodal activity with the activity density peaks in late June and mid August in 2004 (Fig. 2). This pattern was not clear in 2005, when the activity density levels were generally lower (Fig. 2).

\subsection{Species-specific accounts}

\subsubsection{Nebria brevicollis (Fabricius)}

The seasonal activity of $N$. brevicollis was bimodal. The species was most abundant in the urban site in both years (Fig. 3). There was an early high activity during week 24 in both years and all habitats, while the late high activity occurred during weeks 40-41 (Fig. 3). The activity patterns were consistent, except that the activity did not seem to stop in the middle of the summer in the urban habitat, unlike in the other two habitats (Fig. 3).

\subsubsection{Carabus nemoralis Müller}

The seasonal activity of $C$. nemoralis was bimodal or slightly bimodal in all sites and years (Fig. 4). In five of the six site-year combinations studied, the spring activity density was higher than the autumn one; the only exception was in the suburban habitats in 2005 (Fig. 4). It is likely that this species remains active in the autumn longer than the trapping period. At the forest site, this species showed slight bimodality with decreasing activity towards the end of the season in 2004 . The spring activity peaked in early July, but the autumn peak was not clearly identifiable. The autumn activity peak in 2005 was almost missing (Fig. 4). In the suburban sites, the species thrived: the activity density of this species was the highest in this habitat in both years, with an early high activity in week 24 and equally high activity in week 39 in 2004. The urban habitat was characterised by strong early activity, occurring about 4 weeks earlier than elsewhere (Fig. 4). It is also possible that this species became active before the start of the trapping. The second activity period was a little weaker in 2004, again starting earlier in the urban area than elsewhere.

\subsubsection{Carabus hortensis Linnaeus}

This species occurred at the suburban and forest sites, but was entirely absent from the urban area in both years. It was much more abundant in the forest than in the suburban habitats in both years, although less so in 2005. This species had a distinct activity peak in late August-early September, more pronouncedly in the suburban habitats than in the forest (Fig. 5). The activity peak occurred later in the suburban than the forest habitat in both years, but the spring activity peak was virtually absent in the suburban habitat in 2005 (Fig. 5). The activity density levels were similar in both years, and 2005 seemed to be a better year for this species in the suburban habitat than 2004 (Fig. 5).

\subsubsection{Carabus coriaceus Linneaus}

This species had similar activity at the sites and years (Fig. 6) and occurred in the forest and suburban sites, with a few adults captured at the urban site in 2004. It was active in the mid and late season. The early activity period extended from 

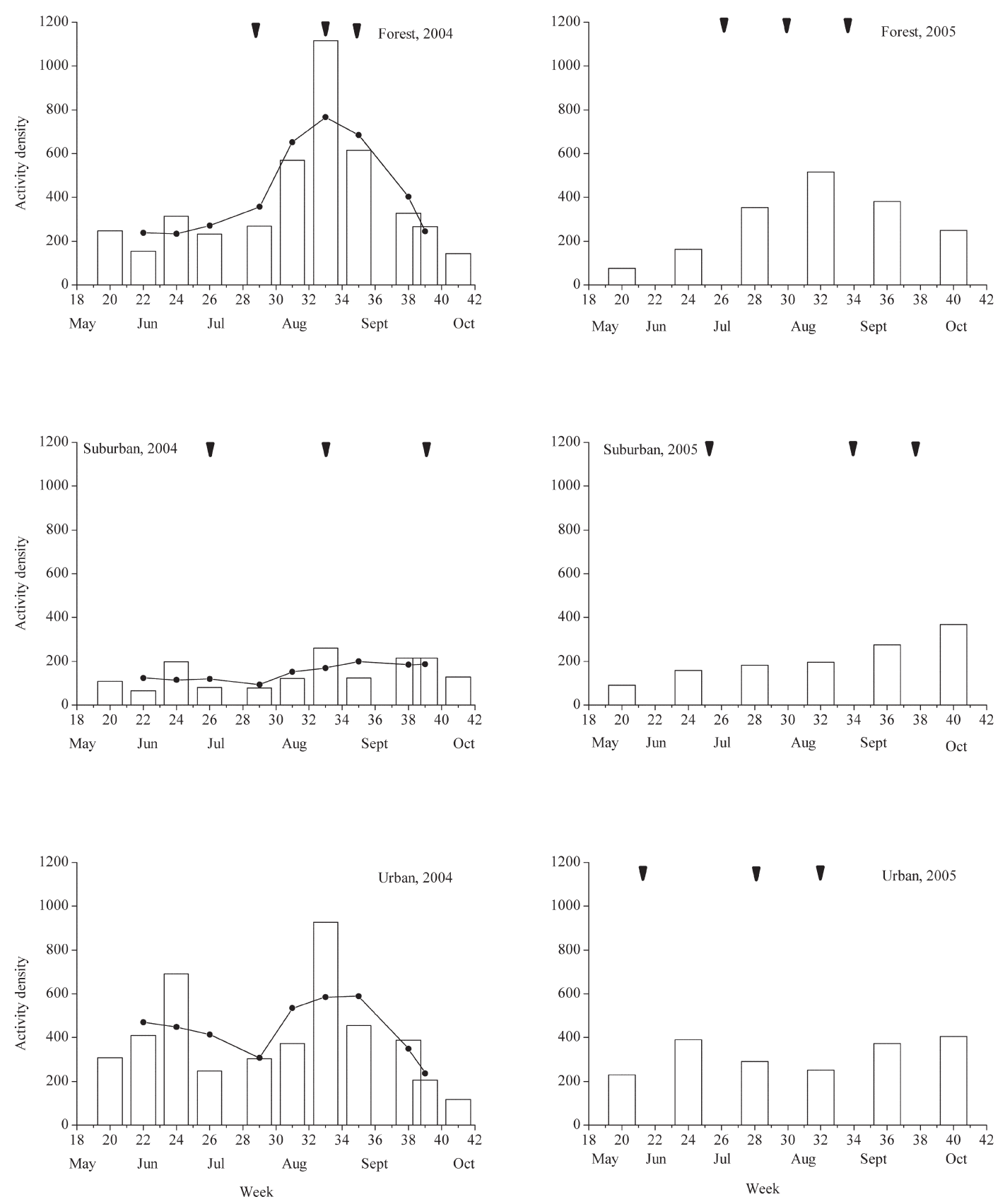

Fig. 2. Seasonal dynamics of six ground beetle speceis in forested, suburban and urbanised habitats in Sorø, West Zealand, Denmark. Black arrows indicate start, peak and the end of main activity period, respectively. Bars indicate activity density (no. of individuals / trap $\times$ fortnight) from start to end of sampling. Line on 2004 panels indicates running means of three weeks (and thus start on $2^{\text {nd }}$ sampling occasion and ends earlier than sampling did). Running means were not calculated for 2005 , due to few sampling occasions.

May to mid-August, while the main activity period was restricted to August and September. The late activity period lasted until October. The ac- tivity density was slightly lower in 2005 than in 2004 in the forest, and much more so in the suburban habitat (Fig. 6). 

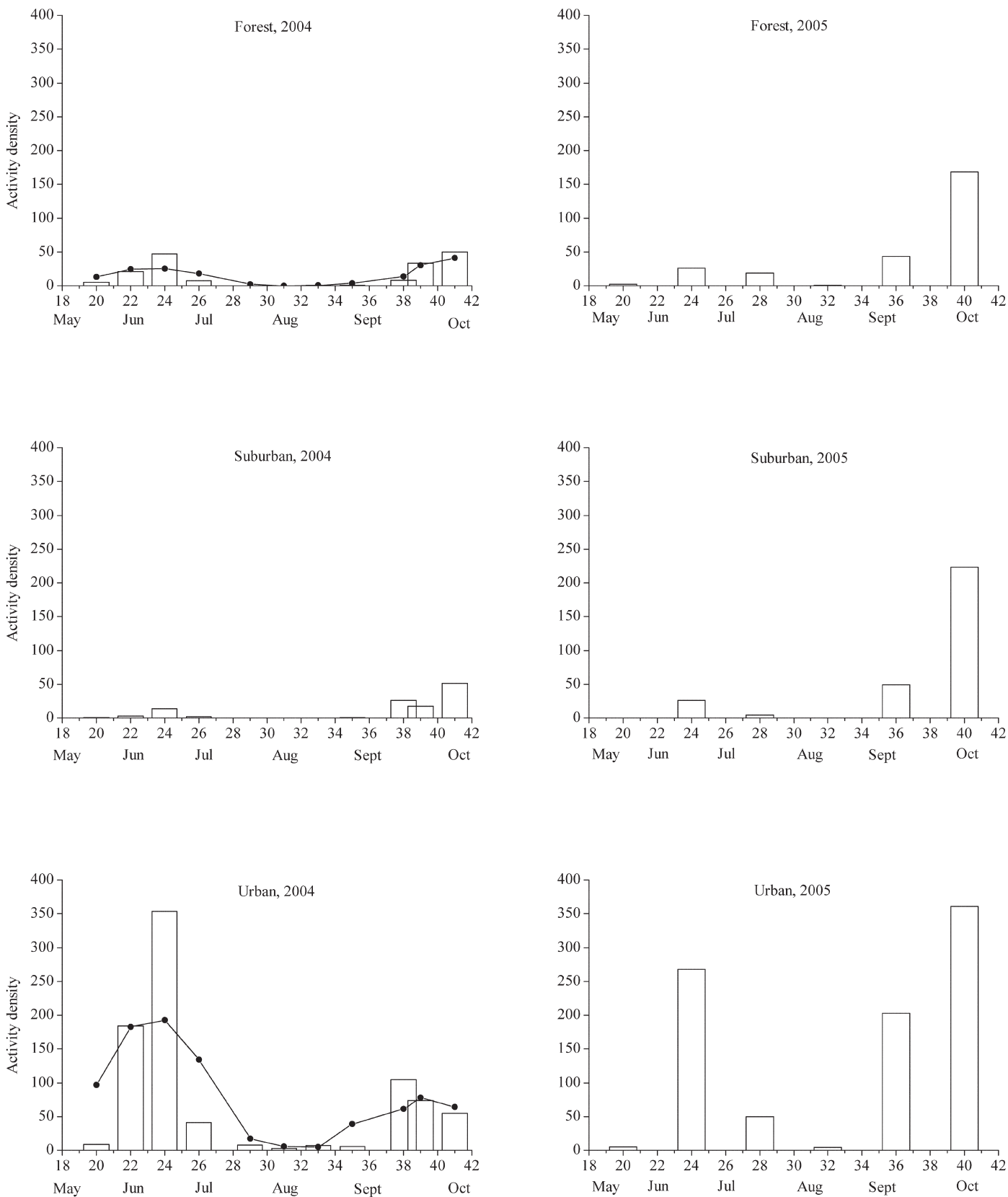

Week

Week

Fig. 3. Seasonal dynamics of Nebria brevicollis at the three urbanisation stages (original forest, suburban, and urban forest remnants) in Sorø, West Zealand, Denmark. Black arrows indicate start, peak and the end of main activity period, respectively. Bars indicate activity density (no. of individuals / trap $\times$ fortnight) from start to end of sampling. Line on 2004 panels indicates running means of three weeks (and thus start on $2^{\text {nd }}$ sampling occasion and ends earlier than sampling did). Running means were not calculated for 2005 , due to the few sampling occasions. 

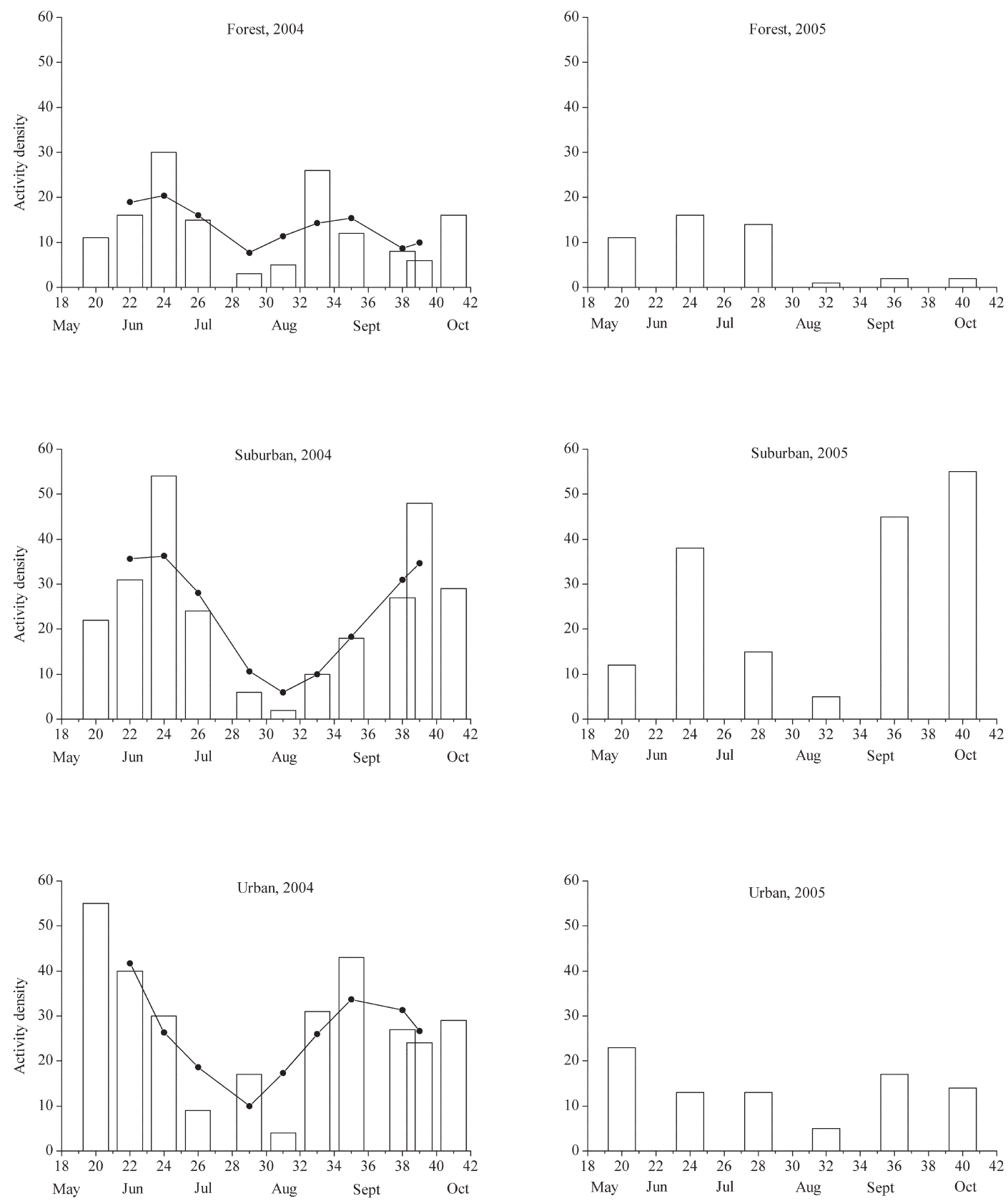

Week

Week

Fig. 4. Seasonal dynamics of Carabus nemoralis at the three urbanisation stages (original forest, suburban, and urban forest remnants) in Sorø, West Zealand, Denmark. Black arrows indicate start, peak and the end of main activity period, respectively. Bars indicate activity density (no. of individuals / trap $\times$ fortnight) from start to end of sampling. Line on 2004 panels indicates running means of three weeks (and thus start on $2^{\text {nd }}$ sampling occasion and ends earlier than sampling did). Running means were not calculated for 2005 , due to the few sampling occasions. 

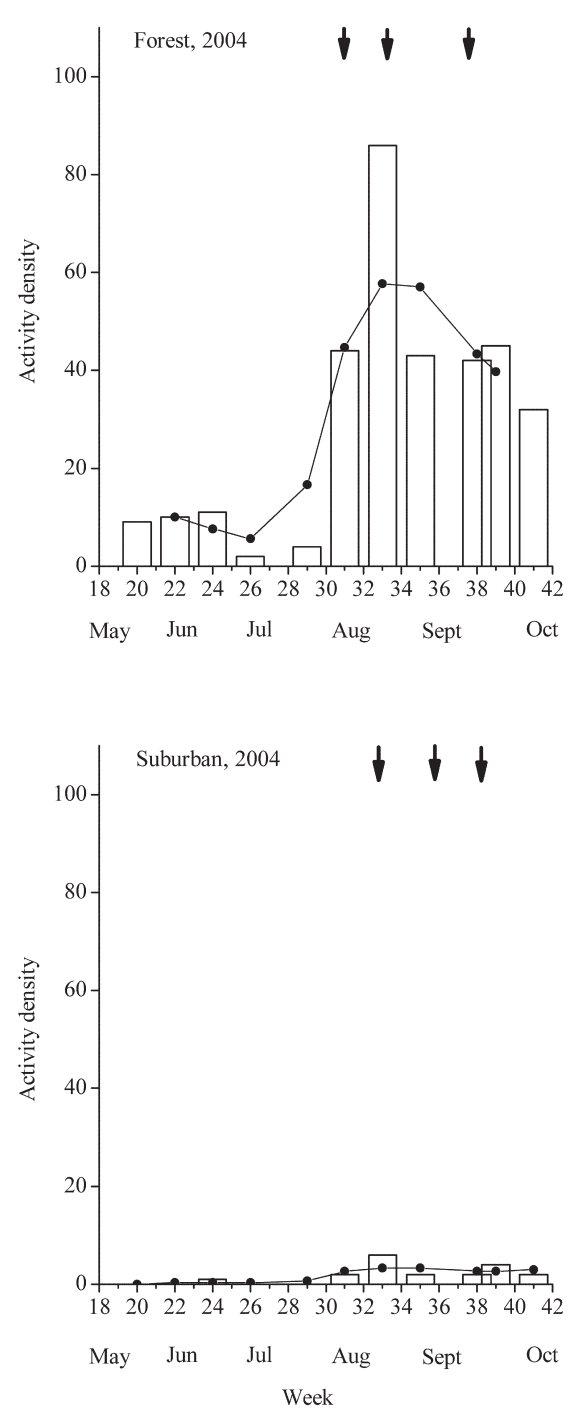

\subsubsection{Pterostichus melanarius (Illiger)}

This species had a similar activity period in both years with the seasonal activity seeming unimodal, or a slightly fused bimodal. Although a slight decrease of activity occurred in week 26 in 2004 in all habitats, this did not appear on the trendline nor anywhere in 2005 (Fig. 7). The main activity period was short, falling between weeks 31-34, peaking in week 33. In the urban habitat, a unimodal activity curve was evident in 2004, with a main activity period (weeks 27-34) and activity peak (week 33) similar to the one in the other two habitats. The overall activity density was higher in 2004 than in 2005 (Fig. 7).
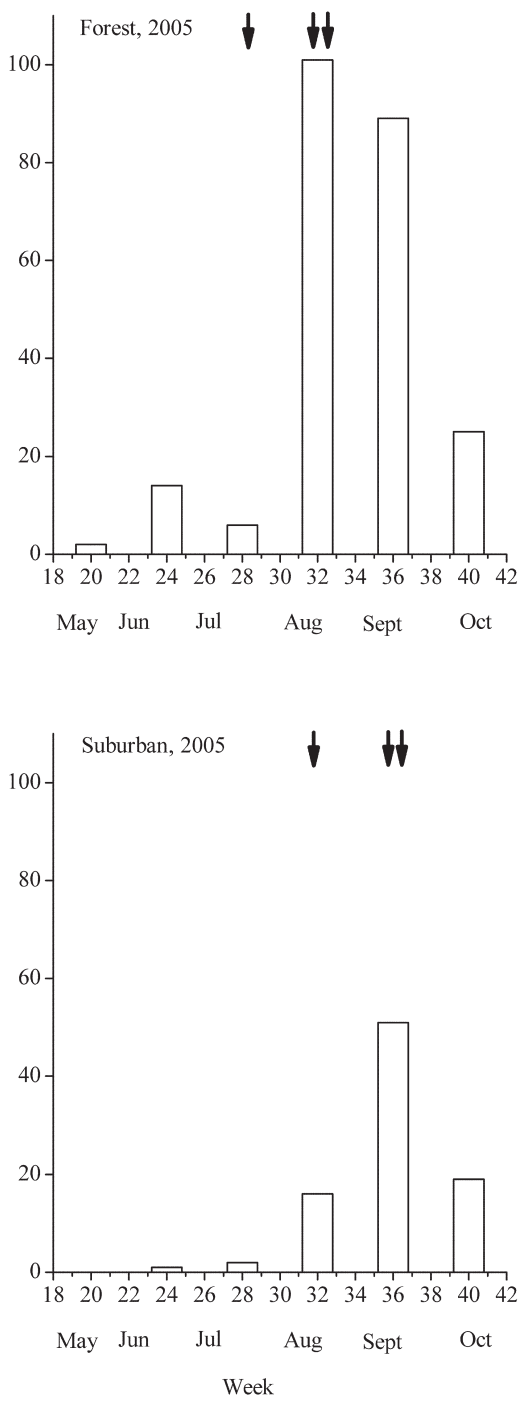

Fig. 5. Seasonal dynamics of Carabus hortensis at the three urbanisation stages (original forest, suburban, and urban forest remnants) in Sorø, West Zealand, Denmark. Black arrows indicate start, peak and the end of main activity period, respectively. Bars indicate activity density (no. of individuals / trap $\times$ fortnight) from start to end of sampling. Line on 2004 panels indicates running means of three weeks (and thus start on $2^{\text {nd }}$ sampling occasion and ends earlier than sampling did). Running means were not calculated for 2005, due to the few sampling occasions.

\subsubsection{Abax parallelepipedus (Piller \& Mitterpacher)}

This species occurred in the forest and suburban sites in both years, but only in 2005 in the urban habitat (Fig. 8). In the forest habitat, the activity was sharply unimodal with the main activity period falling between weeks 26-34 with an activity peak on week 33 . The activity pattern among the habitat types were similar in 2005. In the suburban habitat, the main activity period occurred two and three weeks earlier in 2004 and 2005, respectively, than those in the forest (Fig. 8). In 2004, the activity densities were much higher than in 2005 (Fig. 8). 
Fig. 6. Seasonal dynamics of Carabus coriaceus at the three urbanisation stages (original forest, suburban and urban forest remnants) in Sorø, West Zealand, Denmark. Black arrows indicate start, peak and the end of main activity period, respectively. Bars indicate activity density (no. of individuals / trap $x$ fortnight) from start to end of sampling. Line on 2004 panels indicates running means of three weeks (and thus start on $2^{\text {nd }}$ sampling occasion and ends earlier than sampling did). Running means were not calculated for 2005 , due to the few sampling occasions.
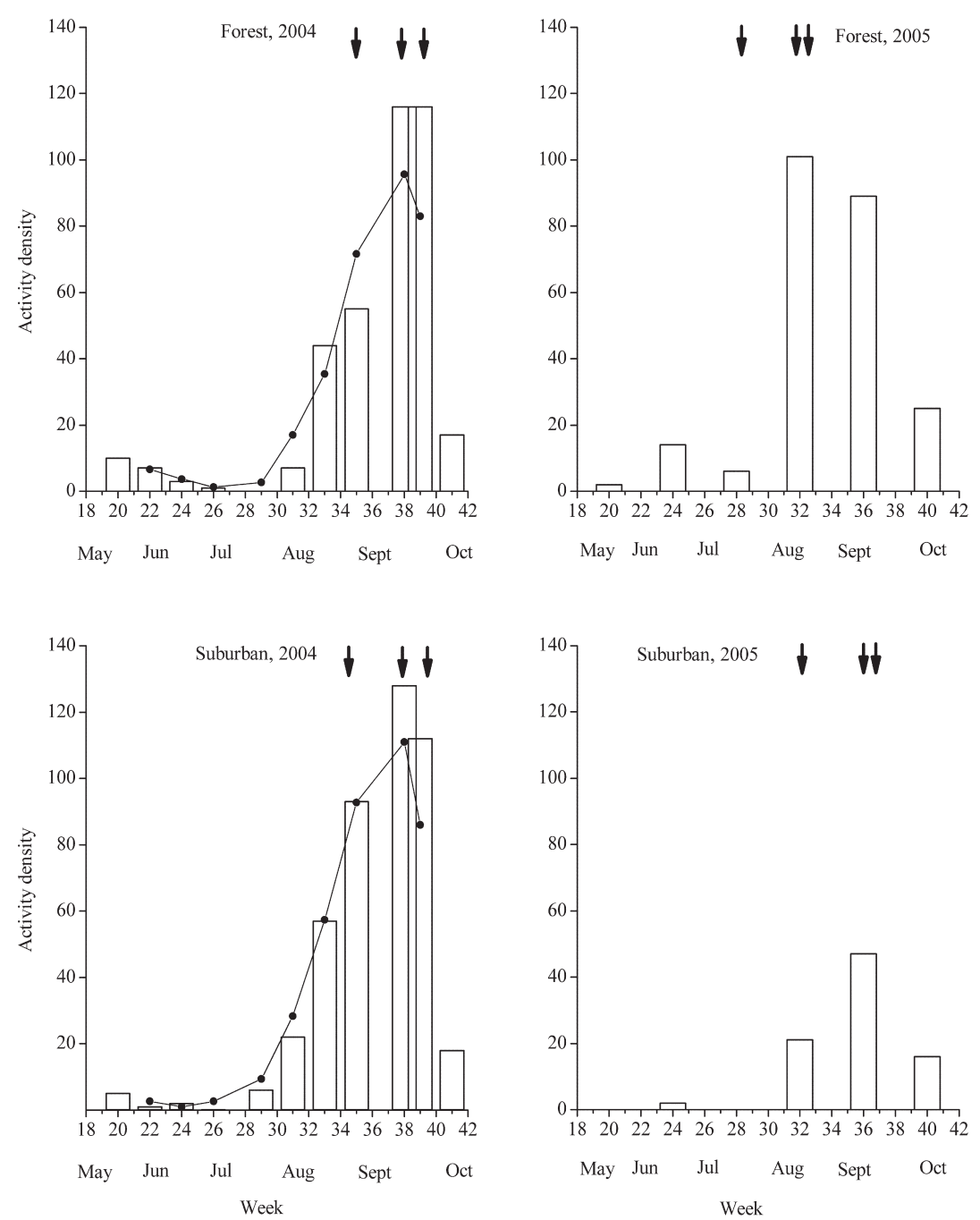

\section{Discussion}

All of the six studied forest species were able to maintain a large and continuously surviving populations (judged from activity densities) in urbanised ( $C$. nemoralis, $P$. melanarius) or suburbanised (the remaining four species) habitats. This indicates that such habitat fragments can provide a way to species survival at the landscape level even under urbanised conditions, although this may depend on the dispersal ability of the species. Abax parallepipedus displays a similar ability in France (Vergnes et al. 2013). In case of N. brevicollis, the forest fragments in the urbanised habitat had higher activity densities, so they can even serve as population source, not sink. This is an in- teresting phenomenon, because urbanised habitats are often considered sink habitats (Padilla \& Rosewald 2015).

Carabids in the northern temperate region are generally active during spring and late summer (Penney 1969, Thiele 1977). This is generally attributed to the food requirements of egg-laying females. Adult-overwintering species emerge in spring and are soon in reproductive condition, producing a spring activity peak. Many otherwise polyphagous species require protein at this life stage (Mayntz et al. 2005), and ground beetles get this from suitable prey, mostly invertebrates (Larochelle 1990). Invertebrate activity in spring is influenced mainly by temperature, which is more capricious in spring than in summer-au- 

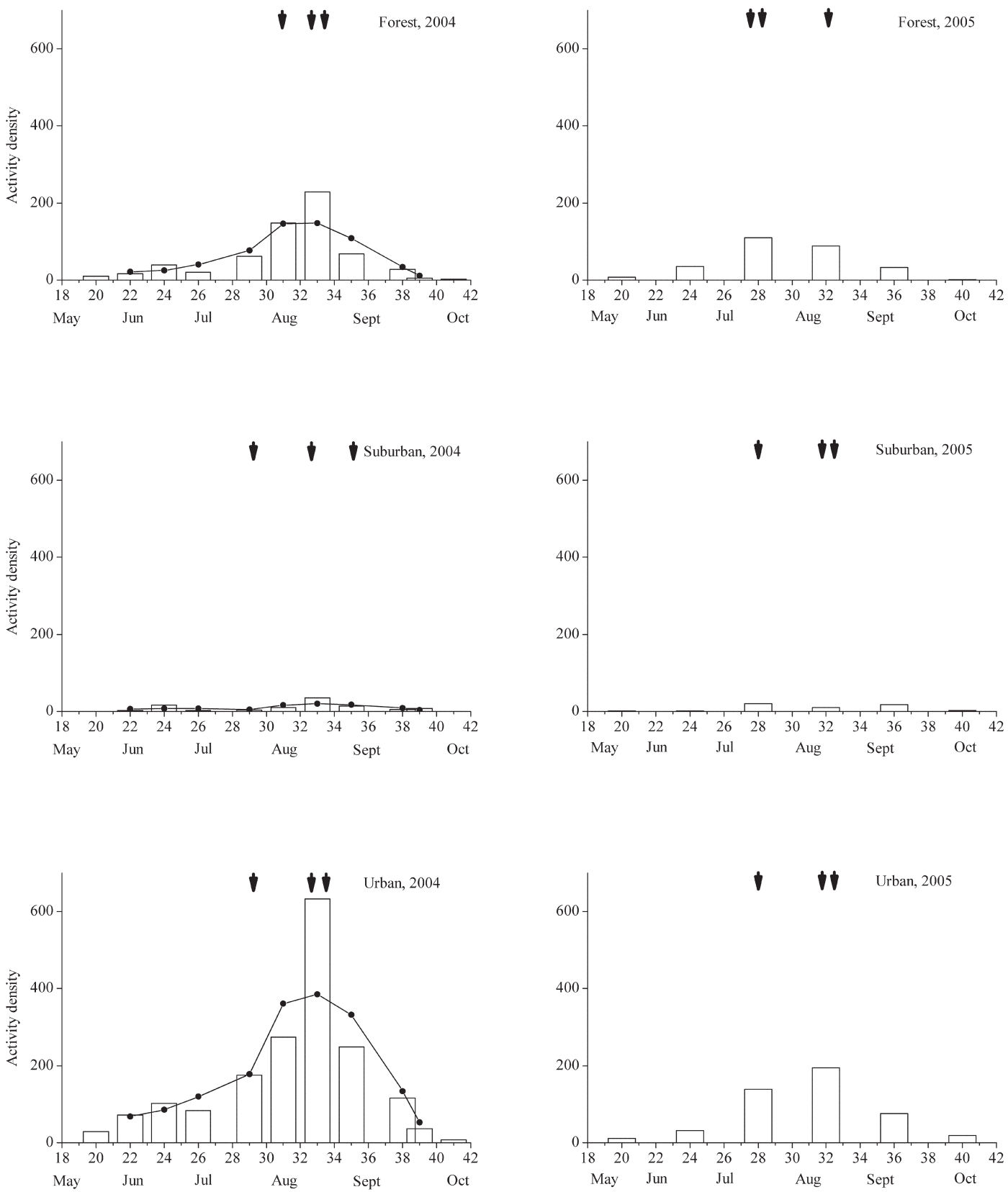

Week

Week

Fig. 7. Seasonal dynamics of Pterostichus melanarius at the three urbanisation stages (original forest, suburban, and urban forest remnants) in Sorø, West Zealand, Denmark. Black arrows indicate start, peak and the end of main activity period, respectively. Bars indicate activity density (no. of individuals / trap $\times$ fortnight) from start to end of sampling. Line on 2004 panels indicates running means of three weeks (and thus start on $2^{\text {nd }}$ sampling occasion and ends earlier than sampling did). Running means were not calculated for 2005 , due to the few sampling occasions. 

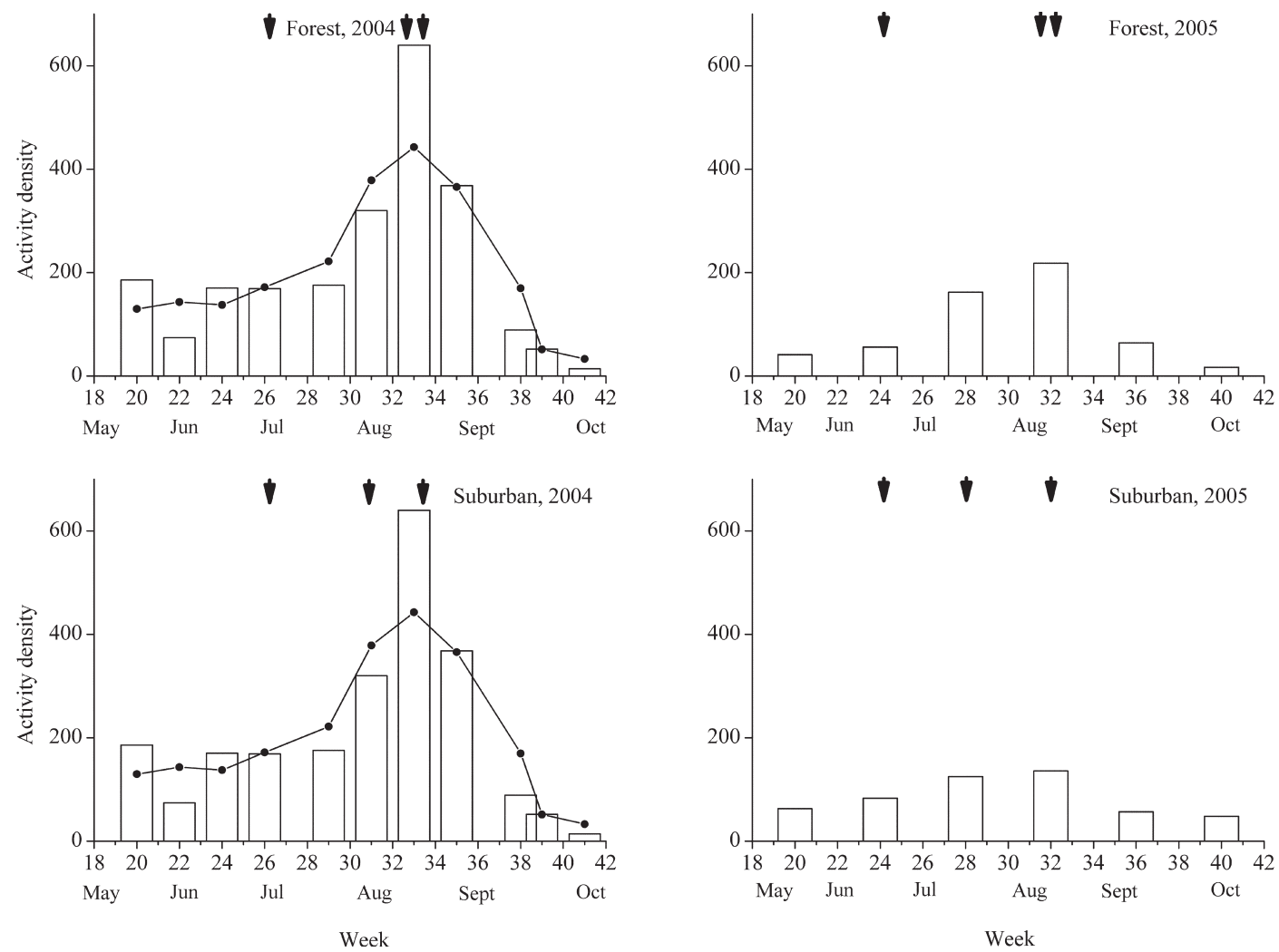

Fig. 8. Seasonal dynamics of Abax parallelepipedus at the three urbanisation stages (original forest, suburban, and urban forest remnants) in Sorø, West Zealand, Denmark. Black arrows indicate start, peak and the end of main activity period, respectively. Bars indicate activity density (no. of individuals / trap $\times$ fortnight) from start to end of sampling. Line on 2004 panels indicates running means of three weeks (and thus start on $2^{\text {nd }}$ sampling occasion and ends earlier than sampling did). Running means were not calculated for 2005 , due to the few sampling occasions.

tumn. Consequently, more between-site and between-year variation in the early seasonal activity period can be expected for such species than for those breeding late summer-early autumn. The late summer-early autumn peak is mostly caused by species overwintering as larvae, complete their development in spring, emerge and reproduce. Several species reproduce more than once, creating two reproductive periods that sometimes become two "reproductive subpopulations" (Kádár et al. 2015). The same species can have different habitat preferences in different parts of their distribution range (Tyler 2008) and their activity patterns can also be different (Butterfield 1986, Matalin 2006), which makes studies of seasonal activity in different locations worthwhile. However, studies rarely go beyond registering the fact that there can be/are differences in seasonal dy- namics (e.g. Matalin 2006). Seasonal dynamics are influenced by both inherent rhythms and random local events, like cold spells or rainy periods. Such "noise" has the potential to confound the underlying pattern, and the use of a standardised, quantitative method to describe seasonal activity (Fazekas et al. 1997), followed here, allows to reduce the impact of local "noise" on the pattern, making between-site comparisons more feasible and interpretable.

In Denmark, there is a scarcity of life-history and seasonal dynamics studies of carabids (but see e.g. Schjøtz-Christensen 1965, 1968, Jørum 1976a, b). All species studied here showed clear differences in seasonality, sometimes also between the different studied habitats.

Two main groups can be distinguished. The first one consists of the species with constant sea- 
sonality ( $C$. hortensis, $C$. coriaceus, and A.parallelepipedus), in which the activity profiles among sites and years did not differ remarkably.

Carabus hortensis showed consistent activity pattern with slight unimodality among the years and sites. This consistency was also documented by Jørum (1976a). The autumn activity did not decrease at the end of the trapping period, corresponding to Schjøtz-Christensen's (1968) findings at Mols, on the Jutland Peninsula of Denmark. This species overwinters as larvae, and has low dispersal power, so its presence indicates suitable habitat conditions for individual development, and the maintenance of self-supporting population.

Carabus coriaceus showed a consistent unimodal activity pattern like $C$. hortensis. Kålås (1985) found a unimodal activity pattern also in western Norway, but the activity peak occurred a month earlier. In Jutland, however, the same species had a bimodal activity pattern (Jørum 1976a) with a second activity peak in late September. In Hungary, the activity period of $C$. coriaceus preceded that of $C$. hortensis (Kádár et al. 2015).

The unimodal activity pattern by $A$. parallelepipedus was similar to that found in Jutland (Jørum 1976a).

The second group consists of the species with flexible seasonality ( $N$. brevicollis, $C$. nemoralis, and $P$. melanarius), in which there were remarkable differences among sites and years.

Nebria brevicollis showed between-year constancy in the urban, but not in the suburban and forest habitats. The bimodal activity curve of $N$. brevicollis was clearly observed at Sorø. The characteristic diapause in July and August corresponds to other findings in Denmark (Jørum 1976a, b) and Norway (Kålås 1985), and can be explained by the photoperiod-governed aestivation that characterises this species (Thiele 1969). In five of the six year-samples, the autumn activity density was higher than the spring one. The temporal changes in the activity density are fast, because the emergence of teneral adults leads to a rapid increase in the number of individuals (Penney 1969). These individuals may migrate to other habitats, and could have caused the time lag in the increase of the number of individuals in the suburban area. The late activity peaks in the suburban and forest habitats indicate that these sites are less favourable for this species, and therefore these sites could be sink habitats.

Carabus nemoralis, which is a spring breeder, showed bimodality with varying tendencies among sites. The peak activity periods were in June and October, which corresponds to the findings by Kålås (1985) in western Norway. A smaller bimodality seems to occur also in the Netherlands (Turin 2000), but in northern Scandinavia, the species develops over two years (Lindroth 1985). It is likely that the size of the second peak depends on temperature: in warmer years, more newly emerged adults show surface activity.

Pterostichus melanarius showed unimodal, or fused bimodal activity pattern with activity peak varying between July and August, corresponding to the findings in Jutland (Jørum 1976a). However, in Norway, the high activity period occurs a month earlier (Kålås 1985). The same species shows a biennial life-cycle in Hestehave at Kalø, Jutland (Jørum 1980), probably just coincidentally because of the extreme climatic conditions during the specific study period. Indeed, Matalin (2006) documented large variations in the life-cycle of $P$. melanarius, probably driven by climatic differences. Females of this species can overwinter and reproduce again the following spring. Jørum (1980), for example, found $30 \%$ of old females having eggs relatively early in the season. This could cause the observed activity pattern.

Considering all the six species studied here, the overall activity density was highest in the forest and urban habitats both years. In the suburban sites, a less consistent activity pattern was found.

High (early) spring activity occurred regularly in species at the urban habitats. In suburban areas, the pattern was less consistent: there was broad variation in the occurrence of spring and autumn activity periods. In the forest, autumn activity peaks were more frequent. This may have a simple cause, like increased temperature in cities, which makes urban forest fragments warmer than continuous forests (Landsberg 1981).

The species with constant activity $(C$. hortensis, C. coriaceus, and A. parallelepipedus) had high activity in autumn, while the species with flexible seasonality ( $N$. brevicollis, $C$. nemoralis, 
and $P$. melanarius) had a bimodal activity pattern with high activity periods in both spring and autumn.

Acknowledgements. We thank the Sorø Akademi Stiftelse for permission to work on their land, Director Mr. Jens Thomsen, Anders Grube, J. Jakobsen, H.-B. Christiensen, H. P. Ravn for their kind assistance, and anonymous reviewers for their suggestions. This study was partially funded by a Danish International School for Biodiversity Studies (ISOBIS) grant (ZE), the Hungarian Scholarship Board (ZE), the Department of Life Sciences and Chemistry, University of Roskilde (AH, ME), the Domus Hungarica Foundation, Budapest, Hungary (GLL), and Aarhus University. This is publication no. 10 of the Danglobe Project.

\section{References}

Butterfield, J. E. L. 1986: Changes in life-cycle strategies of Carabus problematicus over a range of altitudes in Northern England. — Ecology 11: 17-26.

Croci, S., Butet, A., Georges, A., Agujedad, R. \& Clergeau, P. 2008: Small urban woodlands as biodiversity conservation hot-spot: a multi-taxon approach. Landscape Ecology 23: 1171-1186.

Elek, Z. \& Lövei, G. L. 2005: Ground beetle (Coleoptera, Carabidae) assemblages along an urbanisation gradient near Sorø, Zealand, Denmark. — Entomologiske Meddelelser 73: 115-121.

Elek, Z. \& Lövei, G. L. 2007: Patterns in ground beetle (Coleoptera: Carabidae) assemblages along an urbanisation gradient in Denmark. - Acta Oecologica 32: 104-111.

Fazekas, J., Kádár, F., Sárospataki, M., \& Lövei, G. L. 1997: Seasonal activity, age structure and egg production of the ground beetle Anisodactylus signatus (Coleptera: Carabidae) in Hungary. — European Journal of Entomology 94: 473-484.

Gyldenkaerne, S. \& Ravn, H. P. 1998: Effect of dimethoate and cypermetrin on soil dwelling beetles. Bekæmpelsesmiddelforskning fra Miljøstyrelsen nr. 45. - Danish Environmental Protection Agency, Copenhagen, Denmark. 77 pp.

Hůrka, K. 1996: Carabidae of the Czech and Slovak Republics. Illustrated key. — Kabourek, Zlin, Czech Republic. 565 pp \& 16 plates.

Jørum, P. 1976a: En undersoegelse af loebebillefaunaens sammensaetning og saesonaktivitet i en dansk boegeskov (Coleoptera, Carabidae). (A study on the composition and seasonal activity of the ground beetle fauna of a Danish beech forest). - Entomologiske Meddelelser 44: 81-99. [In Danish.]

Jørum, P. 1976b: Life cycle and population density of Nebria brevicollis F. (Coleoptera, Carabidae) in a Danish beech forest. - Videnskabelige Meddelelser fra Dansk naturhistorisk Forening 139: 245-261.
Jørum, P. 1980: Life cycles and annual activity patterns of Pterostichus melanarius (Illig.) and P. niger (Schall.) (Coleoptera: Carabidae) in a Danish beech wood. Entomologiske Meddelelser 48: 19-25.

Kádár, F., Fazekas, J. P., Sárospataki, M. \& Lövei, G. L. 2015: Seasonal dynamics, age structure and reproduction of four Carabus species (Coleoptera: Carabidae) living in forested landscapes in Hungary. - Acta Zoologica Hungarica 61: 57-72.

Kulkarni, S. S., Dosdall, L. M. \& Willenborg, C. J. 2015: The role of ground beetles (Coleoptera: Carabidae) in weed seed consumption: a review. - Weed Science 63: 355-376.

Kålås, J. A. 1985: Species composition and seasonal activity patterns of Carabidae (Col.) in a small deciduous forest in western Norway. — Fauna Norvegica 32: 28 32.

Landsberg, H. 1981: The Urban Climate. - Academic Press, New York. 275 pp.

Larochelle, A. 1990: The food of Carabidae. — Fabrieres Suppl. 5, 1-132.

Lindroth, C. H. 1985: The Carabidae (Coleoptera) of Fennoscandia and Denmark. Fauna Entomologica Scandinavica, Vol. 15, part 1. - E. J. Brill, Leiden, The Netherlands. 224 pp.

Lindroth, C. H. 1986: The Carabidae (Coleoptera) of Fennoscandia and Denmark. Fauna Entomologica Scandinavica, Vol. 15, part 2. - E. J. Brill, Leiden, The Netherlands. 497 pp.

Lövei, G. L. \& Magura, T. 2016: Ground beetle (Coleoptera: Carabidae) diversity is higher in narrow hedges composed of a native compared to non-native trees in a Danish agricultural landscape. - Insect Diversity and Conservation. DOI: 10.1111/icad.12210.

Lövei, G. L. \& Sunderland, K. D. 1996: Ecology and behaviour of ground beetles (Coleoptera: Carabidae). Annual Review of Entomology 41: 231-256.

Lövei, G. L., Magura, T., Sigsgaard, L. \& Ravn, H. P. 2002: Patterns, of ground beetles (Coleoptera: Carabidae) assemblages in single-row hedgerows in a Danish agricultural landscape. - In: Szyszko, J., den Boer, P. \& Bauer, T. (eds), How to protect or what we know about Carabid beetles: 201-212. Proceedings of the $10^{\text {th }}$ European Carabidologist' Meeting. Agricultural University Press, Warsaw, Poland. 378 pp.

Lövei, G. L., Toft, S. \& Axelsen, J. A. 2005: Composition and diversity of spring-active carabid beetle assemblages in relation to soil management in organic wheat field in Denmark. - In: Lövei, G. L. \& Toft, S. (eds), European Carabidology 2003: 173-182. Proceedings of the $11^{\text {th }}$ European Carabidologists' Meeting. Danish Institue of Agricultural Sciences Report no. 114. 401 pp.

Matalin, A. V. 2006: Geographic variability of the life cycle in Pterostichus melanarius (Coleoptera, Carabidae). - Entomological Review 86: 409-422.

Mayntz, D., Raubenheimer, D., Salomon, M., Toft, S. \& Simpson, S. J. 2005: Nutrient-specific foraging in invertebrate predators. - Science 307: 111-113.

McDonnell, M. J. \& Hahs, A. K. 2008: The use of gradient 
analysis studies in advancing our understanding of the ecology of urbanising landscapes: current status and future directions. - Landscape Ecology 23:11431155

Niemelä, J., Kotze, J., Ashworth, A., Brandmayr, P., Desender, K., New, T., Penev, L., Samways, M. \& Spence, J. 2000: The search for common anthropogenic impacts on biodiversity: a global network. - Journal of Insect Conservation 4: 3-9.

Niemelä, J., Kotze, J. D., Venn, S., Penev, L., Stoyanov, I., Spence, J., Hartley, J. \& Montes de Orca, E. 2002: Carabid beetle assemblages (Coleoptera, Carabidae) across urban-rural gradients: an international comparison. - Landscape Ecology 17: 387-401.

Padilla, B. J. \& Rosewald, A. D. 2015: Avian metapopulation dynamics in a fragmented urbanizing landscape. - Urban Ecosystems 18: 239-250.

Penney, M. M. 1969: Diapause and reproduction in Nebria brevicollis (F.) (Coleoptera: Carabidae). - Journal of Animal Ecology 38: 219-233.

Sapia, M., Lövei, G. L. \& Elek, Z. 2006: Effects of varying sampling effort on the observed diversity of carabids (Coleoptera: Carabidae). - Entomologica Fennica 17: 345-350.

Schjøtz-Christensen, B. 1965: Biology and population studies of Carabidae of Corynephoretum. - Natura Jutlandica 11: 1-173.
Schjøtz-Christensen, B. 1968: Some notes on the biology and ecology of Carabus hortensis L. (Col., Carabidae). - Natura Jutlandica 14: 127-151.

Thiele, H. U. 1969: The control of larval hibernation and of adult aestivation in the carabid beetles Nebria brevicollis F. and Patrobus atrorufus Stroem. - Oecologia 2: 347-361.

Thiele, H. U. 1977: Carabid beetles in their environments. - Springer, Berlin, Germany. 369 pp.

Turin, H. 2000: De nederlandse loopkevers. [The Dutch ground beetles]. — Nationaal Natuurhistorisch $\mathrm{Mu}$ seum Naturalis \& European Invertebrate Survey, Leiden. 666 pp. [In Dutch.]

Tyler, G. 2008: The ground beetle fauna (Coleoptera: Carabidae) of abandoned fields, as related to plant cover, previous management and succession stage. - Biodiversity and Conservation 17: 155-172.

Vergnes, A., Chantepie, S., Alexandre, R. \& Clergeau, P. 2013: Are urban green spaces suitable for woodland carabids? First insights from a short-term experiment. - Journal of Insect Conservation 17: 671- 679.

Vergnes, A., Pellissier, V., Lemperiere, G., Rollard, C. \& Clergeau, P. 2014: Urban densification causes the decline of ground-dwelling arthropods. - Biodiversity and Conservation 23: 1859-1877. 